\title{
COVID-19 screening in outpatients with risk factors and healthcare workers
}

\author{
Svenja Ravioli · Thomas Stoeckli · Gregor Lindner
}

Received: 20 May 2020 / Accepted: 29 June 2020 / Published online: 17 July 2020

(C) Springer-Verlag GmbH Austria, part of Springer Nature 2020

\section{Letter to the editors}

\section{Dear Editors,}

Since December 2019 the coronavirus pandemic has confronted physicians worldwide with a new disease associated with cough, fever and dyspnea [1]. In severe cases, lung affection with bilateral infiltrates and subsequent hypoxemia was described [2]. Despite current measures there is still a continuous increase in affected persons all over the world [3].

We report the first analysis of our SARS-CoV-2 screening, established in preparation for the COVID19 pandemic in Switzerland. Ambulatory patients in a good general state of health, consistent with an emergency severity index score of 4 or 5 were screened for COVID-19 by taking a nasopharyngeal swab and performing PCR analysis. The screening was performed according to the following criteria recommended by the Swiss Federal Health Agency [4]: presence of cough or fever and either being a healthcare worker (HCW) or a person with risk factors (PRF) for severe disease, such as age $>65$ years, arterial hypertension, history of cardiovascular disease, chronic pulmonary disease, diabetes mellitus, immunosuppression and active malignant disease.

\footnotetext{
S. Ravioli, M.D. · T. Stoeckli, M.D. · G. Lindner, M.D. ( $₫)$ Department of Internal and Emergency

Medicine, Buergerspital Solothurn,

Schoengruenstrasse 42, 4500 Solothurn, Switzerland

lindner.gregor@gmail.com

S. Ravioli, M.D.

svenja.ravioli@gmail.com

T. Stoeckli, M.D.

thomas.stoeckli@spital.so.ch
}

Between 2 and 31 March a total of 758 HCWs and PRFs with typical symptoms were tested. Cough was present in $667(88 \%)$, fever in $158(21 \%)$, sore throat in $100(13 \%)$, dyspnea in $24(3 \%)$, myalgia in $14(2 \%)$ and anosmia in $2(0.2 \%)$ patients. A total of $344(45 \%)$ tests were carried out in HCWs, including 26 with additional risk factors, while 414 (55\%) were carried out in PRFs. The mean age of HCWs was 39 years $( \pm 17$ years) and $254(74 \%)$ were female. The mean age of PRFs was 49 years ( \pm 17 years) and $233(56 \%)$ were female.

In total $44(5.8 \%)$ tests were positive for SARSCoV-2, 17 (5\%) in HCWs and 27 (6.5\%) in PRFs. Throughout March 2020 the rate of positive tests increased continuously, correlating with the progress of the COVID-19 pandemic in Switzerland. The highest rate of positive test results was noticed on 30 March with $21 \%$ positive results (see Fig. 1 ).

After screening, all persons were initially managed as outpatients, 7 persons with positive test results, $1 \mathrm{HCW}$ and 6 PRFs, needed hospitalization during the course of the disease $(0.92 \%), 6$ recovered well, while 1 person is still critically ill and requires intensive care treatment and mechanical ventilation.

The present analysis confirms the rise in prevalence of positive tests correlating with the extent of the COVID-19 pandemic in Switzerland. As expected, cough and fever proved to be the most prominent symptoms. Interestingly, the hospitalization rate in the screening population remained relatively low even though the majority of positive test results occurred in PRFs. 
Fig. 1 Proportion of positive PCR results for SARSCoV-2 during March 2020

\section{Proportion of SARS-CoV-2 positive screening results}

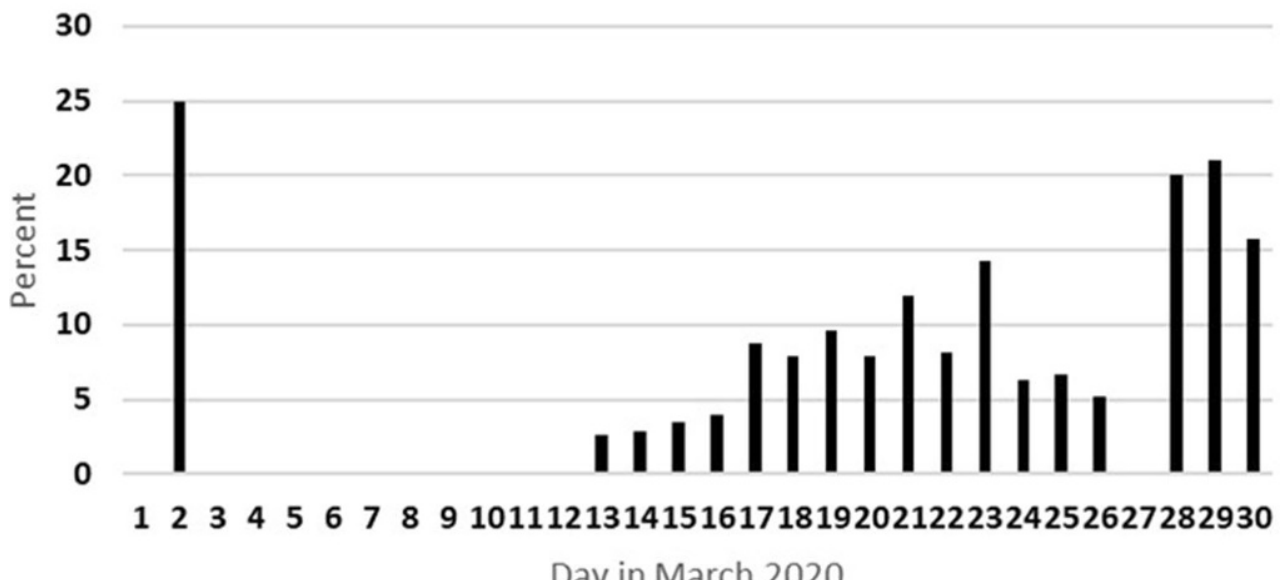

Author Contribution Svenja Ravioli and Gregor Lindner had the idea for the analysis. Thomas Stoeckli, Svenja Ravioli and Gregor Lindner were involved in data gathering and analysis. Svenja Ravioli and Gregor Lindner performed the manuscript draft. All authors critically reviewed the manuscript.

\section{Compliance with ethical guidelines}

Conflict of interest S. Ravioli and T. Stoeckli have no conflict of interest and no financial associations. G. Lindner has no conflict of interest. G. Lindner received consultant fees and fees from Bayer, Fresenius Kabi, Otsuka, Daiichi Sankyo; travel grants from GlaxoSmithKline, Otsuka and Pierre Fabre.

Ethical standards The study (study ID: 2020-00737) was reviewed and approved by the local ethics committee, the Ethikkommission Nordwest- und Zentralschweiz (www.eknz. ch).

\section{References}

1. Paules CI, Marston HD, Fauci AS. Coronavirus infectionsmore than just the common cold. JAMA. 2020; https://doi. org/10.1001/jama.2020.0757.

2. Shi H, Han X, Jiang N, Cao Y, Alwalid O, Gu J, et al. Radiological findings from 81 patients with COVID-19 pneumonia in Wuhan, China: a descriptive study. Lancet Infect Dis. 2020; https://doi.org/10.1016/S1473-3099(20)30086-4.

3. https:// coronavirus.jhu.edu/map.html. Accessed 29. April 2020.

4. . https://www.bag.admin.ch/bag/de/home/krankheiten/ ausbrueche-epidemien-pandemien/aktuelle-ausbruecheepidemien/novel-cov/besonders-gefaehrdete-menschen. html. Accessed 29. April 2020.

Publisher's Note Springer Nature remains neutral with regard to jurisdictional claims in published maps and institutional affiliations. 